\title{
Políticas públicas, medioambiente y comunicación gubernamental
}

\author{
Public policies, environment and government communication
}

\author{
Sergio Ricardo Quiroga sergioricardoquiroga@gmail.com \\ http://orcid.org/0000-0003-2586-6321 \\ Universidad Nacional de San Luis/ \\ Instituto Cultural Argentino de Educación Superior (Argentina)
}

\section{Resumen}

Este informe pretende examinar las políticas de comunicación y la legislación medioambiental de la provincia de San Luis, Argentina en el período 2008-2018. Buscamos reconocer las políticas de comunicación de la legislación medioambiental de la provincia de San Luis, Argentina. La Ley de Libertad de Expresión del Pensamiento y de Información (Ley Nro. I-07352010), que destaca en su artículo 1 y 3 la libertad del ciudadano para pensar, expresarse, conocer, informarse y crear.

Algunos trabajos precedentes han buscado examinar las políticas públicas de comunicación ejercidas desde los principales medios de la provincia de San Luis, sin analizar las acciones del 
estado, actor singular, en el establecimiento y desarrollo de políticas públicas de comunicación buscando el mayor conocimiento ciudadano de los asuntos públicos.

El acceso a la información pública de la provincia de San Luis se encuentra legislado por la Ley Nro. V-0924-2015 que garantiza a cada persona el derecho a solicitar y recibir información de cualquier organismo, en el soporte que corresponda, bajo normas y tiempos establecidos.

La información ambiental es un requisito imprescindible para el ejercicio ciudadano del derecho humano a un medio ambiente sano y los gobiernos deben ofrecer por múltiples acciones y alternativas la información sobre estas cuestiones.

Palabras clave: Políticas públicas; medioambiente; comunicación gubernamental; ciudadanía; personalismo político.

\begin{abstract}
This paper aims to examine the communication policies and environmental legislation of the province of San Luis, Argentina in the period 2008-2018. We seek to recognize the communication policies of the environmental legislation of the province of San Luis, Argentina. The Freedom of Expression of Thought and Information Act (Law Nro. I-0735-2010), which highlights in its articles 1 and 3 the freedom of the citizen to think, express, knows, informs and creates.
\end{abstract}

Some previous works have sought to examine public communication policies exerted from the main media of the province of San Luis, without analyzing the actions of the state, a singular actor, in the establishment and development of public communication policies seeking greater citizen knowledge of the public affairs.

Access to public information of the province of San Luis is legislated by Law Nro. V-0924-2015 that guarantees each person the right to request and receive information from any agency, in the corresponding support, under rules and times established.

Environmental information is an essential requirement for the citizen's exercise of the human right to a healthy environment and governments must offer information on these issues through multiple actions and alternatives.

Keywords: Public policies; environment; governmental communication; citizenship; political personalism.

Medioambiente, sociedad y comunicación son fenómenos de estudio que la academia ha captado tenuemente en los últimos años. La información medioambiental es muy sensible para los ciudadanos por sus implicancias tácitas en la vida social y económica. 
En las sociedades democráticas, los gobiernos deben transparentar sus acciones y sus opciones presupuestarias sobre temas diversos como en materia económica, medioambiental, sanitaria, etcétera. El grado de información política del ciudadano contemporáneo tiene directa incidencia en sus formas, calidad e intensidad participativa, además de que puede ser objeto de manipulación política.

La búsqueda la planteamos desde un enfoque de la comunicación orientada a impulsar, por una parte, la participación organizada, la elaboración de acuerdos colectivos, la construcción democrática de decisiones, el consenso y la acción de los diferentes actores directamente involucrados en el manejo sustentable de los ecosistemas forestales, y por otra, a detonar procesos que propicien la significación y la comprensión social respecto de la problemática ambiental, que permita la experiencia de construir y valorar la relación equitativa entre las personas como condición de la sustentabilidad (Aparicio Cid, 2016).

La comunicación posibilita y establece sinergias entre el cambio del entorno y la transformación de las representaciones del mundo (Serrano, 2009), al constituirse en un componente estratégico de cualquier actividad precisamente porque es un nexo importante entre ambas funciones. La comunicación es además, una dimensión constitutiva de la vida cultural, puesto que "la cultura existe y vive en la medida en que se comunica" (Martín-Barbero, 2008: 14).

\section{San Luis}

San Luis es una provincia argentina situada en la Región de Cuyo de Argentina y que cuenta con aproximadamente 450.000 habitantes. Limita al norte con la provincia de La Rioja, al este con Córdoba, al sur con La Pampa, al oeste con Mendoza y al noroeste con San Juan y desde diciembre de 1983, es gobernada hegemónicamente por el Partido Justicialista. Para Argentina, la permanencia en una provincia de un gobierno por más de treinta años es un hecho singular y llamativo y solo puede explicarse por el personalismo político. Es una forma de representación pero no toda representación es personalista como afirma Mires (2013). Ocurre cuando el representante político tiene a los poderes públicos por su acción y permanencia, sino cuando su presencia cubre la mayoría de espacios y ámbitos relevantes de la política y la cultura hasta el punto de que en lugar de representar un proyecto, empresa que pasa a ser la propia persona del gobernante y la democracia se opaca.

La permanencia por años del mismo grupo de gobernantes del mismo partido en el gobierno, merced a estrategias diversas como el control de los medios de comunicación y periodistas a través de las pautas publicitarias, el control y fuerte influencia del gobernador (poder ejecutivo) 
sobre las otras áreas (poder legislativo y poder judicial) construye en las sociedades latinoamericanas una democracia opaca (Quiroga, 2016). La ausencia de periodistas profesionales en los medios, la escasa inmersión de los periodistas universitarios en los medios y organizaciones de la sociedad civil en general o la imposibilidad de estos medios de poder pagarles salarios adecuados a los periodistas.

Si suscribimos que la democracia es una cultura y una presentación, podemos decir al igual que Fernando Mires (2013) en Personalismo y Política que la "política es representación, la representación es simbólica y el símbolo es y será siempre una persona". En la mayoría de los países latinoamericanos ocurre que la política está signada por un extremo personalismo, fenómeno que puede ser explicado de diversas maneras pero en donde confluyen distintos factores. El subdesarrollo político es esencial para el surgimiento de culturas políticas personalistas que también se expresan en un subdesarrollo económico y la irrupción de masas heterogéneas que podrían hacer imprescindible la presencia de un hombre fuerte en condiciones de concentrar todo el poder en su torno y una posible derivación constituciones presidencialistas que confieren al ejecutivo atribuciones casi omnímodas son fenómenos que pueden explicar el desarrollo del personalismo en la región latinoamericana.

\section{Comunicación de gobierno}

También es idea de este trabajo descriptivo proponer un conjunto de ideas para promover un proyecto innovador con el propósito de aportar a las políticas gubernamentales. Buscamos proponer iniciativas para la mejora de la comunicación medioambiental, como parte de las políticas públicas de un gobierno.

Nos preguntamos a los fines de orientar esta inicial indagación:

- ¿Qué información del medio ambiente ofrece el gobierno?

- ¿A través de qué medios?

- ¿Existe interacción entre gobierno y ciudadanía en temas medioambientales?

- ¿Cuál es la participación ciudadana en temas medioambientales?

La comunicación gubernamental recrea la gestión del gobierno y los temas de ecología, medioambiental y el cambio climático son sensibles para una ciudadanía cada vez más propositiva y participativa. Usualmente la gestión del estado democrático requiere la difusión y comunicación de información pública de calidad a sus ciudadanos. Se trata de que todos los 
ciudadanos pueda tener acceso a la información mediante todos los procedimientos que sirvan para transparentar la gestión pública, mediante la difusión de la información por medios múltiples, el intercambio comunicativo, la garantía de la protección de los datos personales, el favorecimiento de la rendición de cuentas a los ciudadanos, la mejora de la organización, clasificación y manejo de los documentos y la contribución a la democratización de la sociedad. Los temas de medioambiente son sensibles para la prensa y los ciudadanos. Un desastre ecológico o la aparición sorpresiva de un fenómeno natural rápidamente despiertan el interés de los medios de comunicación y de los ciudadanos. En San Luis la aparición de un nuevo río en 1985 originó preocupaciones de la ciudadanía sobre la sorpresa del fenómeno natural que el gobierno de la provincia tuvo que asumir. En este sentido, las explicaciones del gobierno aclararon y dieron algunas respuestas a las preocupaciones ciudadanas sobre la emergencia de aguas subterráneas.

Por otro lado, entendemos que la relación sociedad-naturaleza como una relación de naturaleza compleja, conflictiva y dinámica, ya que la sociedad y las condiciones naturales están siempre en proceso de transformación. La sociedad tiene diferentes actores sociales con intereses particulares (estado, empresas, organizaciones, etcétera) en medio de factores políticos, económicos y culturales. La relación sociedad-naturaleza es dinámica porque las sociedades en cada época histórica, han transformado el medio natural de diversas maneras para obtener los elementos necesarios para subsistir. El conflicto entre la sociedad y la naturaleza se da cuando los diferentes actores sociales poseen distintos intereses 0 resignifican de manera distinta sobre los recursos naturales. Estas pujas construyen los conflictos donde los actores participantes luchan por la presencia en las agendas políticas y mediáticas.

\section{La información ambiental}

La comunicación medioambiental promueve procesos de toma de decisiones sociales sobre el manejo de ecosistemas involucrando los actores relacionados con una problemática particular, de la apropiación de responsabilidades de grupos que se benefician de estos sistemas naturales y de la cooperación de los actores clave y de la población en general, con el fin de negociar soluciones y de influir en las políticas que inciden en dicha problemática, profundizando en la búsqueda de acuerdos sectoriales (Aparicio Cid, 2016).

Toda información pública que esté disponible es beneficiosa u útil para los ciudadanos. La información ambiental es un tipo de información particular y tenerla de parte del gobierno, 
constituye un requisito imprescindible para el ejercicio de la ciudadanía. Es también parte del derecho humano al medio ambiente sano y el gobierno debe ofrecer por múltiples acciones y alternativas toda la información sobre estas cuestiones. El acceso a la información favorece la apertura y transparencia en la toma de decisiones y permite a los ciudadanos confiar de las decisiones adoptadas por las autoridades. La participación ciudadana informada es además, un mecanismo para integrar las preocupaciones y el conocimiento de la ciudadanía en las decisiones de políticas públicas que afectan al ambiente.

La riqueza de perspectivas y dimensiones que confluyen en la construcción de la noción de comunicación ambiental abre múltiples posibilidades para establecer una definición conceptual en función del valor otorgado a ciertos atributos o componentes (Aparicio Cid, 2016).

\section{Políticas públicas}

Arellano Gault y Blanco señalan que las políticas públicas en un marco democrático son

aquellas decisiones y acciones legítimas de gobierno que se generan a través de un proceso abierto y sistemático de deliberación entre grupos, ciudadanos y autoridades con el fin de resolver, mediante instrumentos específicos, las situaciones definidas y construidas como problemas públicos (2013: 27).

Desde una dimensión conceptual, para entender qué son las políticas públicas, es necesario diferenciar dos conceptos que en idioma español no tienen traducción: Politics (política), policies (políticas). El primero es entendido como las relaciones de poder, los procesos electorales, las confrontaciones entre organizaciones sociales con el gobierno. El segundo tiene que ver más con las acciones, decisiones y omisiones por parte de los distintos actores involucrados en los asuntos públicos (Aguilar Astorga y Lima Facio, 2009).

Hoy, por un lado, los gobiernos, más allá de su tamaño, buscan fortalecer estos procedimientos promoviendo la buena gobernanza ambiental ante la creciente demanda de la ciudadanía por participar en la toma de decisiones que afecta a su entorno y por otro lado, la publicidad y la transparencia de los actos de gobierno constituyen un pilar fundamental en las instituciones democráticas, cuya calidad institucional se eleva en la medida que los ciudadanos puedan recibir, información completa, veraz, adecuada y oportuna. Los gobiernos buscan fortalecer sus procesos comunicativos ante la creciente demanda de la ciudadanía por información y participación. 
Existen escasos trabajos sobre estas preocupaciones en materia de políticas públicas. Ponce, Maldonado, Chiriani, Oro (2016) realizan un análisis sobre las políticas públicas de comunicación ejercidas desde los principales medios de la provincia de San Luis, sin analizar las acciones del gobierno en el establecimiento y desarrollo de políticas públicas de comunicación que busque mayor conocimiento ciudadano de los asuntos públicos. La contribución de Ponce et al. (2016) enfoca la actuación de los medios de comunicación digitales y se proponen describir las políticas públicas de comunicación ejercidas desde los principales periódicos online de la provincia de San Luis, Argentina y sus efectos en la construcción de ciudadanía. Resulta complejo conocer sobre los efectos de los medios en la construcción de ciudanía cuando diversos estudios advierten sobre una pérdida de consideración y confianza de los ciudadanos en los medios de comunicación, en general. Los sujetos en este caso, ciudadanos son quienes realizan prácticas sociales y son actores con distintos poderes en la construcción de la ciudadanía.

Ponce et al. (2016) concluyen que en un gobierno democrático los medios de comunicación se constituyen en actores centrales que pueden influir en el desarrollo de las políticas públicas al hacer visible un problema, acelerar su desarrollo o influir sobre otros actores, tales como gobernantes y gobernados. Si los medios de comunicación exponen un problema ciudadano es porque ese hecho posee condiciones para su tratamiento y expansión en la opinión pública, tiene valores-noticias para el medio y ha sido detectado por la cultura profesional de los periodistas.

\section{Estructura de acceso a la información pública en San Luis}

Una sociedad puede disponer de muy buenas legislaciones en materia de acceso a la información, pero el gobierno puede no querer exponer toda la información pública a la ciudadanía o en el caso de querer hacerlo, no contar con los medios, con la estrategia o con buenos profesionales de la comunicación.

Tener legislación sobre acceso a la información pública es beneficio y útil para los ciudadanos, pero no siempre el gobierno cumple con las leyes que lo regulan.

\section{Leyes}

La Ley de Libertad de Expresión del Pensamiento y de Información (Ley Nro. I-0735-2010), que destaca en su artículo 1 y 3 la libertad del ciudadano para pensar, expresarse, conocer, informarse y crear. 
Por otro lado, el acceso a la información pública de la provincia de San Luis permite a los ciudadanos de San Luis conocer más de las acciones del gobierno. Se encuentra legislado por la Ley V-0924-2015 que garantiza a cada persona el derecho a solicitar y recibir información de cualquier organismo de gobierno, en el soporte que corresponda, bajo normas y tiempos establecidos.

toda persona tiene derecho, de conformidad con el principio de publicidad de los actos de gobierno, a solicitar y a recibir información completa, veraz, adecuada y oportuna, de cualquier órgano perteneciente a: La Administración Central y Descentralizada; los Entes Autárquicos; los Organismos Inter-jurisdiccionales integrados por la provincia de San Luis; las Empresas y Sociedades del Estado, las Sociedades Anónimas con participación estatal mayoritaria, Sociedades de Economía Mixta y todas aquellas otras Organizaciones Empresariales donde el Estado Provincial tenga participación en el capital"...etc (Ley V0924-2015, artículo 1).

\section{Derechos de la ciudadanía}

En cuanto a los derechos de la ciudadanía, la Ley de Libertad de Expresión del Pensamiento y de Información (Ley Nro. I-0735-2010), que destaca en su artículo № 1 y $\mathrm{N}^{\circ} 3$ la libertad del ciudadano tanto para pensar, como para expresarse, conocer, informarse y crear. En su artículo 1 la norma afirma que "...garantiza en todo su territorio la Libertad de Pensamiento, Expresión, Conocimiento, Información y de Ideas como atributo esencial de toda persona. Ninguna Ley ni autoridad puede restringir la libre expresión y difusión de las mismas". En el artículo 3 se señala que

todos los ciudadanos tienen derecho a información veraz y a escoger libremente los servicios que quieran recibir, sin que los intereses privados y los poderes públicos puedan interferir ni sustituir sus decisiones. El pluralismo en la comunicación es una condición esencial para el cumplimiento de la libertad de expresión, de información y de comunicación, y garantiza la libre formación de opinión pública, la diversidad y la cohesión social. La prestación de servicios de comunicación debe basarse en el respeto y la protección de los principios, los valores y los derechos fundamentales que reconoce la Constitución, en especial el derecho al honor, el derecho a la intimidad y el derecho a la propia imagen (Ley Nro. I-0735-2010, artículo 3).

A nivel nacional está vigente la Ley de Derecho de Acceso a la Información Pública (Ley 27275) que en su artículo 2 establece el: 
Derecho de acceso a la información pública. El derecho de acceso a la información pública comprende la posibilidad de buscar, acceder, solicitar, recibir, copiar, analizar, reprocesar, reutilizar y redistribuir libremente la información bajo custodia de los sujetos obligados enumerados en el artículo $7^{\circ}$ de la presente ley, con las únicas limitaciones y excepciones que establece esta norma.

La Ley presume pública toda información que generen, obtengan, transformen, controlen o custodien los sujetos obligados alcanzados por la norma legal. En su artículo 3 se establece como

a) Información pública: todo tipo de dato contenido en documentos de cualquier formato que los sujetos obligados enumerados en el artículo $7^{\circ}$ de la presente ley generen, obtengan, transformen, controlen o custodien", en su inciso

b) Documento: todo registro que haya sido generado, que sea controlado o que sea custodiado por los sujetos obligados enumerados en el artículo $7^{\circ}$ de la presente ley, independientemente de su forma, soporte, origen, fecha de creación o carácter oficial.

El artículo 4 de la norma se establece que "toda persona humana o jurídica, pública o privada, tiene derecho a solicitar y recibir información pública, no pudiendo exigirse al solicitante que motive la solicitud, que acredite derecho subjetivo o interés legítimo o que cuente con patrocinio letrado". En su artículo 5 sobre la entrega de la información la norma afirma que

la información debe ser brindada en el estado en el que se encuentre al clasificarla. El Estado tiene la obligación de entregarla en formatos digitales abiertos, salvo casos excepcionales en que fuera de imposible cumplimiento o significara un esfuerzo estatal desmedido. Las excepciones las fijará la Agencia de Acceso a la Información Pública.

En su artículo 6 se establece la gratuidad del acceso a la información. Como suele suceder con las normas que regulan los asuntos públicos y que los gobernantes deben cumplir, a menudo los puntos de ambigüedad de las normas y el desinterés de los propios gobiernos por cumplirlas, hace que éstas queden como expresiones de buenos deseos en el papel.

\section{Ciudadanía, política y desinterés ciudadano}

El investigador Uranga (2011) se pregunta qué es primero en el marco de la mutua interdependencia entre ciudadanía política y comunicación. Se cuestiona quien es el configurador y quien es el configurado. ¿Quién configura a quién? Un ciudadano es una 
persona o un grupo que pertenece a una comunidad política, social y económica. Omar Rincón afirma "la ciudadanía es una figura política" (2004). Pero, qué ocurre en San Luis, una provincia de pequeñas proporciones frente al resto, con índices macroeconómicos aceptables y un gobierno de carácter personalista que apela al populismo como forma de gestión y como característica de su accionar electoral.

La sociedad sanluiseña asiste en general con cierto desinterés a los asuntos públicos en la provincia de San Luis. La apatía de los ciudadanos por la cosa pública es una cultura radicada desde hace tiempo que incluye desesperanza, desconfianza y resignación sobre los gobiernos que elige y sus propuestas de campañas incumplidas. El desinterés por la marcha del gobierno y sobre el desarrollo de sus políticas públicas en materia social, educativa, etcétera; políticas públicas en materias diversas, a la confección de sus propias estadísticas, al manejo de la distribución de la publicidad oficial en los medios y periodistas que determina la baja calidad informativa, etcétera.

\section{Medios de comunicación}

Los medios de comunicación no actúan con independencia del sistema político y su presencia en el espacio público debe examinarse por las influencias e interacciones que generan en la opinión pública y por la multiplicidad de factores que en las organizaciones mediáticas condicionan el periodismo actual. Medios y periodistas han experimentado sensibles transformaciones en los últimos años la crisis de los medios de comunicación tradicionales, los cambios en las audiencias, etc. Internet y la progresiva digitalización de la sociedad ha modificado el panorama de los medios y los públicos.

Los medios de comunicación en general, construyen y elaboran sus visiones sobre la realidad., presentando ésta en base a su propio sistema de valores, sus rutinas productivas, sus niveles de decisión, sus criterios de calidad, sus criterios de oportunidad y sus criterios de pertinencia formulando una realidad mediática (La Rosa, 2013).

En el proceso colectivo de construcción de agenda, medios, gobiernos y ciudadanía se influyen recíprocamente (quién influye a quién), ya que los mensajes noticiosos contienen los indicios de su contexto comunicativo y de los escenarios en los que son construidos.

La provincia de San Luis tiene diversos medios de comunicación gráficos, radiales, televisivos y digitales. El Diario de la República (empresa privada), Canal 13 San Luis (canal televisivo de administración gubernamental) y Agencia de Noticias San Luis (ANSL) medio digital del gobierno son algunos de los principales medios que la administración provincial tiene para 
imponer los puntos de vista del gobierno sobre los asuntos públicos y una ausencia notable de voces opositoras. Existen en la provincia, más de cien radios de frecuencia modulada y distintos canales de televisión privados.

\section{Medios de San Luis}

\section{El Diario de la República}

El 2 de mayo de 1966 nació El Diario de San Luis, fundado por Hernando Pérez para narrar las principales notas de la vida sanluiseña. En los primeros años de vida, el medio experimentó constantes cambios en el sistema de impresión, procesos que tuvieron influencia en la calidad de una publicación. En 1984 se transfirió el medio de comunicación a Nahuel S. A. que realizó diversas inversiones, incorporando nueva tecnología en un contexto favorable con la naciente democracia argentina. El medio gráfico de alcance provincial, resultó y es uno de los mayores receptores de la publicidad de las empresas radicadas en la provincia de San Luis y de la publicidad gubernamental desde 1984 y tiene una buena planta de periodistas y medios técnicos. El 17 de julio de 1992, el medio cambio su nombre pasando de llamarse El Diario de San Luis a una nueva denominación: El Diario de la República.

Otro medio es Periodistas en la Red, de Juana Koslay, en San Luis, Capital (http://www.periodistasenlared.com.ar) es un diario digital y con una estructura mínima que produce los contenidos del sitio, con una línea editorial crítica hacia el gobierno provincial.

También está La Gaceta Digital (http://www.lagaceta-digital.com.ar) cuenta con información de alcance provincial con diversidad y pluralidad informativa y San Luis Noticia (http://www.sanluisnoticia.com.ar) cuenta con cobertura informativa provincial. Otro medio es Notinogo (http://notinogo.blogspot.com.ar) posee información de carácter local y regional.

El esquema de medios puede describirse como un sistema en donde conviven actores como los públicos, gobierno y medios en el ejercicio de la ciudadanía. 


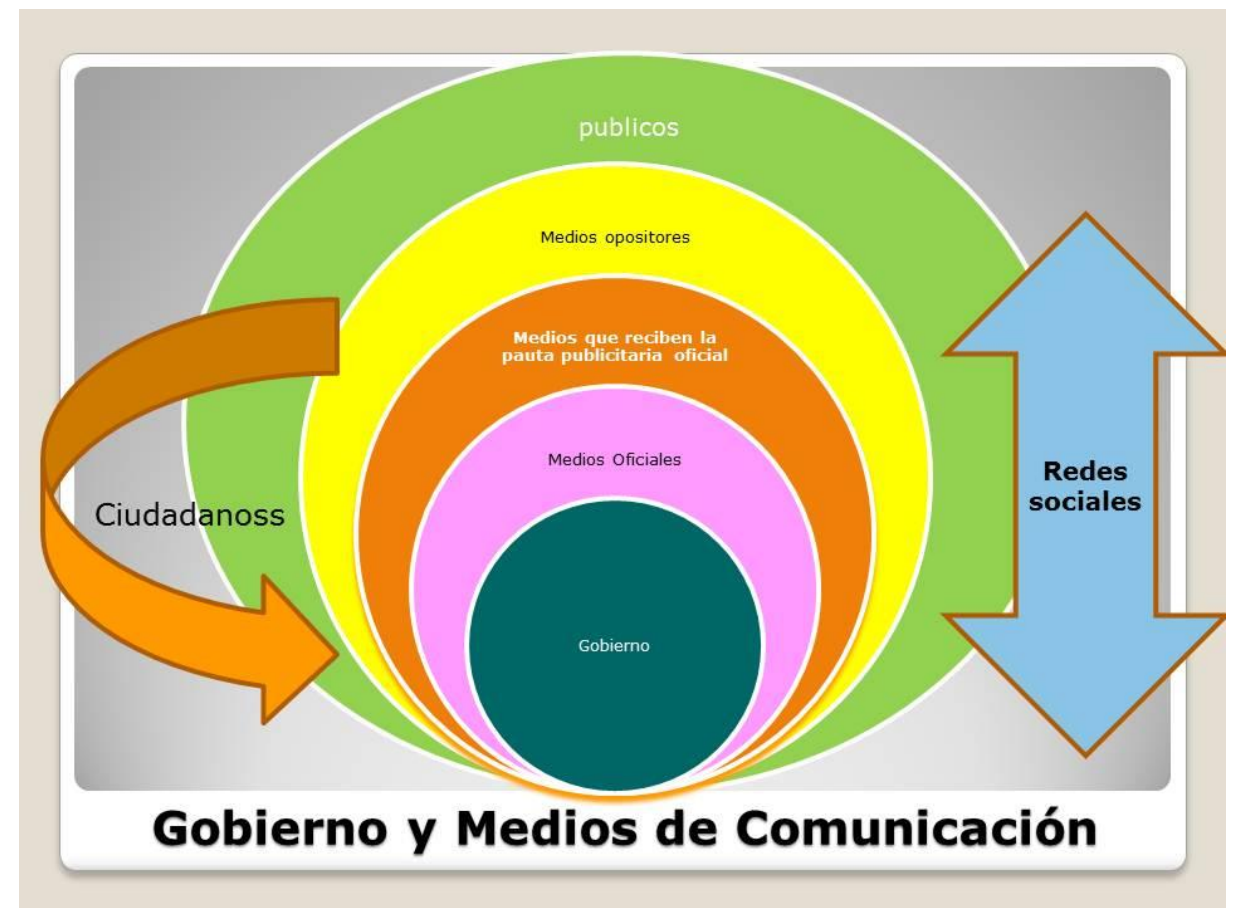

Diagrama 1. Medios y ciudadanía (elaboración del autor)

No debemos olvidar, que Stephen Lukes (2014) ideó un modelo tridimensional de poder que no era ostensiblemente sobre los medios. La primera dimensión del poder es el medio general que las personas consumen, o los textos particulares que eligen y que ejercen influencia y poder. La segunda dimensión del poder es el establecimiento de agenda de temas en las que las personas deben pensar y la tercera dimensión del poder es aquella factibilidad que tienen los medios para moldear intereses y deseos.

El concepto de "agenda" plantea sus dificultades, ya que designa "la conciencia de existencia de un objeto y de la importancia relativa que se le atribuye" (Charron, 1998: 81) y se presenta como una lista jerarquizada de temas. Como aclara el propio Charron (1998), empleada para "designar el contenido de las noticias, es más lo que oculta que lo que aclara de su objeto" (Charron, 1998: 81) y de acuerdo con este autor, olvida algunas de las dimensiones importantes de la información periodística como de las retóricas, la sustancia de los mensajes, ni de los códigos mediáticos.

En San Luis temas controversiales que atañen por ejemplos al monto de los viáticos del gobernador, al surgimiento de las llamadas "escuelas generativas" o la aparición en la Cuenca del Morro de un nuevo río llamado "Nuevo Río" no han sido objeto de polémicas o debates ciudadanos. 
Las escuelas generativas ha sido una nueva propuesta educativa en la provincia de San Luis lanzada en 2017 bastante polémica. Estas escuelas, -según el gobierno provincial - intentan dar oportunidades diferentes en diversos contextos, profundizando los significados de la experiencia escolar, el aprendizaje, la aparición de nuevos formatos pedagógicos y las estrategias de enseñanza. Sin embargo, otros aspectos del sistema educativo como los salarios docentes, las instalaciones educativas, los recursos educativos, no aparecen en la consideración de los discursos oficiales sobre educación.

Guiñazú Palumbo (2014) infiere que los bajos niveles de participación ciudadana de los ciudadanos sanluiseños obedecen a diversos motivos como la escasa información y difusión de los canales gubernamentales para ejercitarla pese a la inicial creación de mecanismos como los procesos de Presupuesto Participativo o la Auditoría Ciudadana y la falta de confianza de la ciudadanía en las instituciones gubernamentales. Por otro lado, en términos constitucionales existe, la iniciativa popular, que es otra posibilidad de participación de los ciudadanos, es reconocida en el artículo 97 de la Constitución de la provincia de San Luis. La norma establece que "se reconoce a los ciudadanos la iniciativa popular para la presentación de proyectos de ley, que son avalados con el porcentaje que la misma determine, el que debe ser superior al ocho por ciento del padrón electoral". Quedan excluidos de las peticiones ciudadanas por esta vía, los asuntos de tratados, presupuestos, creación y derogación de tributos provinciales y la reforma de la propia constitución. En el presupuesto participativo los ciudadanos pueden proponer obras, pero el gobierno finalmente determina la posibilidad de realización de las mismas. Esta norma de la constitución de San Luis, es de difícil concreción y nunca se ha usado en el contexto provincial.

Guiñazu Palumbo (2014: 45) señala que "la ciudadanía no dispone actualmente de alguna causa o razón de gravedad que la movilice". En su tesis, se infiere que la ciudadanía de San Luis no participa en los asuntos públicos debido a que no tiene grandes temas que la convoquen. Según el autor, hasta 2013 y posiblemente hasta 2015, San Luis se encontraba en el contexto argentino en una posición de relativa estabilidad política y económica, porque tenía bajo nivel de deuda pública, era acreedor de la administración nacional, poseía una planta de empleados públicos que si bien era reducida con los años se incrementó progresivamente con pasantes, desempleados del denominado Plan de Inclusión, y la instalación de nuevos planes sociales (2015-2016), cifras que son tomadas para las estadísticas oficiales como "personas empleadas".

La conclusión de Guiñazú Palumbo (2014) es que la ciudadanía no participa activamente en las decisiones gubernamentales en el hecho de que algunas de las necesidades básicas de la población estén medianamente satisfechas. Esta situación erosionaría las iniciativas de 
participación de la ciudanía, en coincidencia con la idea de Oscar Oszlak (2012) cuando afirma que:

la participación ciudadana no se produce sólo porque la población sea invitada por un gobierno a hacerlo. Debe haber, para ello, una oportunidad, que no depende únicamente de la existencia de canales facilitados desde el estado: las ocasiones más propicias suelen ser aquellas en que un sector de la población se ve amenazado por una política que entraña algún tipo de menoscabo o riesgo a su situación actual (2012: 19).

Es posible que -como ocurre con otras comunidades- los convenios, adhesiones y normas medioambientales a la que San Luis adhiere sean desconocidas para una porción importante de su ciudadanía.

El gobierno de la provincia de San Luis ha informado que participa y adhiere a:

- Mediante la Ley IX-335, adhiere a la Ley nacional 24051, que regula la generación, manipulación, transporte, tratamiento y disposición final de residuos peligrosos. Mediante el Decreto 1.322/96 se habilita el Registro Provincial de Generadores y Operadores.

- Código de Aguas de la provincia de San Luis, Ley VI-159-2004.

- La Ley IX-876 establece el marco jurídico aplicable al procedimiento de Evaluación de Impacto Ambiental (EIA).

- Se ajusta al régimen de la Ley X-630 de Tránsito y Seguridad Vial y su Decreto Reglamentario 2507/09. La misma ha sido modificada por la Ley X-0890-2014 en sus artículos 6 y 13.

\section{Leyes y decretos}

Ley 9841-Plan Maestro del Agua 2012-2025.

Ley 9851-Recursos Genéticos y Bioquímicos de la Diversidad Biológica Provincial.

Resolución 2/11-Actividad Forestal.

Resolución 3/11-Evaluación de Riesgos Ambientales.

Resolución 10/11-Programa Gestión Ambiental y Control de Contaminación.

Decreto 6077/07-Planificación Ambiental y Ordenamiento Territorial.

Decreto 4/08-Creación de Organismos dentro del Programa Protocolo de Kyoto.

Decreto 2129/08-Protección Ambiental para la Actividad Minera.

Decreto 565/07-Programa de Control de Gestión Ambiental.

Resolución 42/09-Registro Provincial de Consultores Mineros. 
Resolución 43/09-Gestión Ambiental Minera.

Decreto 2645/08-Prevención Ambiental.

Decreto 1422/08-Control Sanitario Animal.

Decreto 4059/07-Programa de Control de Gestión Ambiental.

Ley 3786-Código de Aguas.

Decreto 116/94-Promoción a las actividades agropecuarias. Método para determinar la elegibilidad de proyectos.

El 2 de enero del 2008, se crea en la provincia de San Luis dentro del Programa Protocolo de Kyoto, una dependencia del Ministerio de Medio Ambiente, cuyos organismos se detallan a continuación:

- Subprograma Proyectos de Mecanismos de Desarrollo Limpio (M.D.L.).

- Área Técnica Operativa de Monitoreo Georeferencial.

- Área Instalación de Viveros y Cultivo.

También se modifica la estructura orgánico-funcional del Programa Protocolo de Kyoto dependiente del Ministerio de Medio Ambiente, aprobada por Decreto 6442-MMA-2006, en la siguiente forma:

"Art. 10. - 4. Programa Protocolo de Kyoto

4.1. Subprograma Proyectos de Mecanismos de Desarrollo Limpio (M.D.L.).

4.2. Área Técnica Operativa de Monitoreo Georeferencial.

4.3. Área Instalación de Viveros y Cultivo.

4.4. Área Control y Ejecución de Forestación"

Estas normas a menudo son desconocidas por la población por la falta de comunicación en general en los medios y por el desconocimiento de la ciudadanía de los temas ambientales en especial.

\section{El Río Nuevo como problemática ambiental}

Existen temas expuestos por los medios que rompen la agenda de los medios por su importancia periodística y la consideración pública. En muchas oportunidades, los gobiernos no prestan atención a particulares problemáticas medioambientales hasta que éstas son expuestas en los medios. 
En 1985 apareció en San Luis (Argentina) un río que fue bautizado como Río Nuevo. Apareció en una zona donde nunca hubo ríos y ha sido parte de un proceso dinámico iniciado en la Cuenca del Morro, ubicada a 110 kilómetros de la capital de San Luis. En 2016 el gobierno de San Luis declaró la Emergencia Pública Ambiental, debido a esta grave situación. El avance del agua dejo campos partidos al medio, rutas cortadas y terrenos colapsados y amenazas latentes sobre distintas poblaciones que estaban en su camino. Este fenómeno que está transformando la geografía de San Luis, se llama "sapping", proceso erosivo generado

De acuerdo a los científicos que estudiaron el fenómeno, el motivo de la aparición de un nuevo rio que tiene zanjones profundos de hasta 25 metros tiene como causas principales la deforestación o el reemplazo de pastizales por cultivos agrícolas. El gobierno de San Luis estableció planes de uso de la tierra y los dueños de la tierra deben presentar un plan que asegure la rotación de cultivos por cinco años y planes de reforestación de la zona. También el gobierno provincial decretó en 2016 la emergencia ambiental en toda el área de la denominada Cuenca del Morro y estableció un plan forestal que buscó disminuir los efectos hídricos del Río Nuevo. Se buscaron plantar tres millones de árboles de rápido crecimiento como álamos, acacias, sauces y cortaderas.

Con el propósito de proteger el medio ambiente, el gobierno de la provincia creó en 2018 la Policía Ambiental, que se encarga de la defensa permanente del medioambiente con la idea de construir una cultura ambiental que fomente el cuidado y la preservación del entorno, mediante campañas y actividades encaminadas a crear conciencia del impacto que generan la acumulación de residuos sólidos y la contaminación de nuestros ríos y diques.

Asimismo, autoridades anunciaron que impulsan la plantación de alfalfa para hacer frente a la problemática ambiental y al desbalance hídrico reconociendo que esa pastura se caracteriza por ser perenne y por absorber gran cantidad de agua.

\section{Conclusiones}

Pese a las buenas intenciones, la información pública del medioambiente ofrecida el gobierno hacia los ciudadanos es aún escasa y los principales canales de comunicación de las mismas son los medios "oficiales" o más cercanos al poder político que gobierna el estado provincial. Existe escasa y una pobre interacción entre gobierno y la ciudadanía en temas medioambientales. Por un lado, el gobierno no promueve la participación de la ciudadanía en los asuntos públicos y por otro lado, los ciudadanos no demuestran demasiado interés en participar, ni en los propios asuntos públicos. La participación ciudadana en una amplia 
variedad de temas en general, y en temas medioambientales en particular, es bastante pobre y limitada.

También el gobierno de San Luis utiliza diversas páginas webs donde coloca noticias que hacen referencia al medioambiente y al campo como (http://ministeriomacp.sanluis.gov.ar/) y (http://www.sanluis.gov.ar/tag/medio-ambiente/). También lo hace con los servicios de prensa gubernamental y con los medios estatales que usa a su servicio como El Diario de la República, Canal 13 San Luis y Agencia de Noticias San Luis (ANSL).

\section{Bibliografía}

Agencia de noticias San Luis (6 de julio de 2018). La Policía Ambiental se encargará de la defensa permanente del medioambiente. Recuperado de https://bit.ly/2R8TEBP

Agencia de noticias San Luis (19 de julio de 2018). San Luis trabaja en un mega plan de alfalfa para combatir el desbalance hídrico de la Cuenca del Morro. Recuperado de https://bit.ly/2Rwn10k

Agosto, W. y Casadei, E. (noviembre de 2013). Índice de Transparencia Presupuestaria Provincial, Área de Desarrollo Económico, Programa de Política Fiscal. Buenos Aires, Argentina.

Aparicio Cid, R. (2016). Comunicación ambiental: aproximaciones conceptuales para un campo emergente. Nueva época, 25, enero-junio, pp. 209-235.

Arellano Gault, D. y Blanco, F. (2013). Políticas públicas y democracia. Instituto Federal Electoral, México.

Recuperado

de http://biblio.ine.mx/janium/Documentos/cuaderno_30.pdf

Charron, J. (1998). Los medios y las fuentes. Los límites del modelo de agenda setting. En Gauthier, G.; Gosselin, A. y Mouchon, J. (Comps.). Comunicación y Política (pp. 72-94). Barcelona, España: Gedisa.

Cheresky, I. (2000). Ciudadanía y opinión pública y medios de comunicación. Recuperado de http://biblioteca.clacso.edu.ar/ar/libros/lasa98/Cheresky.pdf

Garretón, M. (2006). Sociedad civil y ciudadanía en la problemática Latinoamérica actual. En Cheresky, I. (compilador). Ciudadanía, sociedad civil y participación política. Buenos Aires: Miño y Dávila.

Lukes, S. (1974). Power: a Radical View. London: Macmillan.

Guiñazú Palumbo, L. (2014). Gobierno Abierto en San Luis. La experiencia de San Luis Digital en la Administración Pública. (Tesis de Licenciatura). Facultad de Ciencia Políticas y 
Relaciones Internacionales, Universidad Nacional de Rosario (Argentina). Recuperado de https://bit.ly/2BZrMHI.

Jaramillo López, J. (2004). Aporte de la comunicación a la construcción de políticas públicas. Recuperado de https://bit.ly/2SALfDS

Jaramillo López, J. (2012). Propuesta general de comunicación pública. Revista Strategy \& Management Business Review, III(2), pp. 1-17.

La Rosa, A. (2013). Construcción de la agenda Mediática. Una mirada al interior de la organización. Lima, Perú: Universidad de San Martín de Porres.

Luna Pla, I. (2001). Medios de comunicación y democracia: Realidad, cultura cívica y respuestas legales y políticas. Revista Razón y palabra, 23. Recuperado de http://oldversion.razonypalabra.org.mx/anteriores/n23/23_iluna.html

Martín-Barbero, J. (2008). Políticas de la comunicación y la cultura. Claves de la investigación. Documentos cidob. Dinámicas interculturales, 11, (pp. 5-19). Recuperado de https://bit.ly/2AuzwzW

Mata, M. (2006). Comunicación y ciudadanía. Problemas teóricos-políticos de su articulación. Revista Fronteiras-Estudios Mediáticos, VIII(1), Brasil, pp. 5-15.

Mires, F. (2013). Personalismo y Política. Polis: Política y Cultura. Recuperado de https://polisfmires.blogspot.com/2012/12/fernando-mires-personalismo-y-politica.html

Olavarría Gambi, M. (2007). Conceptos básicos en el análisis de las políticas públicas. Documentos de Trabajo, 11. Instituto Nacional de Asuntos Públicos, Departamento de Gobierno y Gestión Pública, Universidad de Chile. Recuperado de https://bit.ly/2lwNjiQ

Oszlak, O. (2012). Gobierno Abierto: promesas, supuestos, desafíos. VIII Conferencia Anual INPAE 2012 "Gobierno Abierto: Por una gestión pública más transparente, participativa y colaborativa", San Juan de Puerto Rico.

Ponce, V.; Maldonado, S.; Chiriani, R. y Oro, P. (25 y 26 de agosto de 2016). Políticas públicas en medios de comunicación digitales. El caso de los principales periódicos online de la provincia de San Luis, República Argentina. Paper de las I Jornadas Nacionales de Investigación de la Uncuyo. Recuperado de http://bdigital.uncu.edu.ar/objetos_digitales/9619/27-ponce-maldonado-otros.pdf

Prats i Català, J. (2005). Modos de gobernación de las sociedades globales. En Cerrillo I. Martínez, A. (coord.). La gobernanza hoy: 10 textos de referencia. Madrid: Instituto Nacional de Administración Pública.

Prats i Catala, J. (2005). La gobernanza democrática como modo de gobernación de nuestro tiempo. Madrid, España: Instituto Nacional de Administración Pública. 
Serrano, M. M. (2009). La producción social de comunicación. Madrid, España: Alianza Editorial.

Toro, J. B. (2001). Conceptos básicos de movilización social. Bogotá: Fundación Social.

Uranga, W. (2004). Democracia y ciudadanía: responsabilidad de los comunicadores. Congreso de la Asociación Boliviana de Investigadores de la Comunicación (ABOIC), Cochabamba.

Recuperado

de

http://www.wuranga.com.ar/images/propios/19_democracia.pdf 